\title{
MODELLING PRICE DYNAMICS IN THE HONG KONG PROPERTY MARKET
}

\author{
Sherry Zhefang ZHOU \\ Management Sciences Department \\ City University of Hong Kong, Hong Kong \\ zhefzhou@cityu.edu.hk \\ Helen Xiaohui BAO \\ Department of Land Economy \\ University of Cambridge, United Kingdom \\ hxb20@cam.ac.uk
}

\begin{abstract}
The property market in Hong Kong plays an important role in the political, social and economic life of this vibrant city. Understanding the dynamics of the market is essential to guide government policy making and investment decisions. Using data collected between 1993 and 2006, this study investigates the monthly returns, volatilities, and time-varying correlations in the residential, office, and retail property markets in Hong Kong. A vector autoregressive (VAR) model is used to examine the conditional mean, and a multivariate generalized autoregressive conditional heteroscedasticity (MGARCH) model is adopted to analyze the conditional variance. The dynamic conditional correlation (DCC) approach is utilized to specify the MGARCH model. All of the property types show strong auto- and cross-correlations, which indicates that the sectors relate to each other closely. All three sectors have higher volatilities when major political and economic events occur. The findings reveal the possibility of balancing investment portfolios between the three sectors in the Hong Kong property market. However, exposure to the residential sector may reduce the chance of investment diversification because of the higher correlation of this sector with the other property sectors.
\end{abstract}

Keywords: Return, volatility, VAR, MGARCH, dynamic conditional correlation.

\section{Introduction}

There has been growing interest in investing in real estate due to its ability to hedge inflation, diversify and balance investment portfolios, reduce risk, and generate a stable flow of income (Hudson-Wilson et al., 2005). The benefits of increasing real estate exposure in portfolios are well documented (see, for example, Maroney \& Naka, 2006; Stevenson, 2004; and Ling \& Naranjo, 2002), but the management of real estate poses challenges for portfolio managers due to the illiquidity issue and the difficulty in diversifying across property types. The introduction of real estate investment trusts (REITs) alleviates the illiquidity problem by securitizing real assets and also creates diversification opportunities. Some REITs specialize in real estate in certain regions (for example, the Japanese property market) or sectors 
(for example, office buildings), and investors can choose to combine different REITs to reduce risk. Other REITs also diversify across regions and/or sectors. In such cases, a sound understanding of the inter-relationships between real estate returns across different market segments is essential for individuals, institutional investors, and REIT managers to make investment decisions.

This is an even more pressing issue in the fast-growing Asian real estate market, where REITs are still in their infancy. There is a need for research on the inter-relationship between real estate sectors and geographic regions in terms of returns and volatility. This study is set in Hong Kong, where real estate plays an essential role in the regional economy. The initial public offering (IPO) of the first Hong Kong REIT, the Link REIT, occurred in November 2005. At the time of writing, there are six REITs in Hong Kong, primarily covering the office and retail sectors (see Table 1 for details). The short history of REITs in this market does not allow risk and return correlations across the six REITs to be fully analyzed, but such a study will help Hong Kong REIT managers to diversify their investment across sectors, and institutional investors to optimize their portfolios by including different REITs. The objective of this study is to examine the inter-relationships between the returns, volatilities, and time-varying correlations in the office, retail, and residential property markets in Hong Kong. By revealing the dynamics of the Hong Kong property market, this study casts light on the opportunities that are available for diversifying investment portfolios, and provides suggestions for the future development of REITs in Hong Kong.

TABLE 1: REITS IN HONG KONG

\begin{tabular}{|l|c|c|l|c|}
\hline \multicolumn{1}{|c|}{ Name } & Date Listed & \# of properties & \multicolumn{1}{|c|}{ Property type } & $\begin{array}{c}\text { Capitalization on } \\
\text { 31-Jul-07 } \\
\text { (HK\$) }\end{array}$ \\
\hline Link & $25-$ Nov-05 & 180 & Retail and Car Park & 35.00 billion \\
\hline Prosperity & $16-$ Dec-05 & 7 & Industrial and Office & 2.09 billion \\
\hline GZI & $21-$ Dec-05 & 4 & Retail, Office, and Hotel & 3.13 billion \\
\hline Champion & 24-May-06 & 1 & Office & 12.26 billion \\
\hline Sunlight & 21-Dec-06 & 20 & Retail and Office & 3.36 billion \\
\hline Regal & 30-Mar-07 & 5 & Hotel & 7.65 billion \\
\hline
\end{tabular}

Research on the Hong Kong real estate market has generally focused on areas other than portfolio management. Intensive studies have been conducted in the areas of housing policy (see, for example, La Grange and Pretorius, 2005; La Grange, 2001; and La Grange and Pretorius, 2000), market efficiency and behaviour (for example, Chau, Wong, and Yiu, 2007; Xiao and Tan, 2007; Wong, Yiu, Tse, and Chau, 2006; Hui and Yue, 2006), housing prices (Yiu and Wong, 2005; Leung and Feng, 2005; Tse, 2002, to name but a few), and the relationship between real estate and other financial 
markets (for example, Lu and So, 2005; Fu and Ng, 2001). There is thus a need for empirical studies on the inter-relationships between real estate sectors in Hong Kong to guide investment decisions.

Evidence has shown the time-varying nature of the correlations between real estate sub-markets (see, for example, Glascock, Lu, and So, 2000). Hence, efforts have been made to examine dynamic volatility and correlation in real estate markets. For example, Cotter and Stevenson (2006) use a vector autoregressive-generalized autoregressive conditional heteroscedasticity (VAR-GARCH) model to study the daily REIT volatility in the US market, and Michayluk, Wilson, and Zurbruegg (2006) conduct a similar study using data from the New York and London Stock Exchanges. However, the BEKK process that they adopted for their GARCH models can only handle low-dimension cases. Details of the limitations of BEKK specification can be found in Section 2. Recent developments in the econometrics field, such as Engle's (2002) dynamic conditional correlation (DCC) specification, offer solutions to this problem. However, applications of these new tools have not been seen in the real estate literature.

This study adds to the literature by conducting a time-series analysis of the inter-relationships between the three property sectors in Hong Kong using a VAR model to analyze the conditional mean and the multivariate generalized autoregressive conditional heteroscedasticity (MGARCH) model to analyze the conditional variance. Engle's (2002) DCC approach is adopted to specify the MGARCH model, which allows us to identify correctly the time-varying volatilities and correlations between the three property submarkets in Hong Kong. The estimation outcomes reveal the possibility of balancing investment portfolios between the three sectors in the Hong Kong property market. However, exposure to the residential sector may reduce the chance of investment diversification because of the higher correlation of this sector with the other property sectors.

The remainder of this paper is structured as follows. The analytical framework is introduced in Section 2, followed by a description of the data and the three property sectors in Hong Kong in Section 3. The empirical findings are presented and discussed in Section 4, and conclusions are given in the final section.

\section{Methodology}

We denote the vector of the property return series as $r_{t}=\left\{r_{k t}\right\}$, where $r_{k t}=\log P_{k t}-\log P_{k t-1,1}$ and $P_{k t}$ is the property price index for series $k$ at time $t, k=1, \ldots, K(K=6$ in this analysis). The model structure employed in this study is

$$
r_{t}=\mu_{t}+\varepsilon_{t}
$$




$$
\begin{aligned}
& \mu_{t} \equiv \mathrm{E}\left(\mathrm{r}_{t} \mid F_{t-1}\right), \text { and } \\
& \mathrm{H}_{t} \equiv \operatorname{Cov}\left(\varepsilon_{t} \mid F_{t-1}\right),
\end{aligned}
$$

where $\boldsymbol{\mu}_{t}$ is the conditional mean of $\boldsymbol{r}_{t}$ given the past information $F_{t-1}, \boldsymbol{\varepsilon}_{t}$ is the shock of the return series at time $t$, and $\mathbf{H}_{t}$ is the conditional covariance matrix of $\boldsymbol{\varepsilon}_{t}$ given $F_{t-1}$. It is assumed that $\boldsymbol{\varepsilon}_{t}$ follows a multivariate normal distribution with a mean of zero and a covariance matrix $\mathbf{H}_{t .} \mathbf{H}_{t}$ is required to be a $\mathrm{K}$ $\times K$ positive-definite matrix. To conduct the empirical analysis, $r_{t}$ is characterized by a VAR process for the mean and an MGARCH process for the variance.

We use the Akaike information criterion (AIC) and one of its variants, the Bayesian information criterion $(B I C)$, to identify the VAR order for the mean. For a given vector time series, the order $p$ is selected such that $\mathrm{AIC}$ (or $\mathrm{BIC})(p)=\min _{0 \leq \leq \leq m} \mathrm{AIC}$ (or $\left.\mathrm{BIC}\right)(i)$, where $m$ is a predetermined positive integer.

Many multivariate GARCH models have been proposed as generalizations of univariate volatility models, such as the diagonal VEC model (Bollerslev, Engle, and Wooldrige, 1988), the BEKK model (Engle and Kroner, 1995), the constant conditional correlation (CCC) model (Bollerslev, 1990), and the dynamic conditional correlation (DCC) model (Engle, 2002). DCC model is adopted in this study because it is superior to other models in that it not only overcomes 'curse of dimension' problem in highdimensional cases but also considers the time-varying correlation which is more common in real applications. These MGARCH models are discussed in more details as follows.

Bollerslev, Engle, and Wooldrige (1988) have proposed the diagonal VEC model, or DVEC $(I, s)$ model,

$$
\mathbf{H}_{t}=\mathbf{A}_{0}+\sum_{i=1}^{l} \mathbf{A}_{i} \otimes\left(\boldsymbol{\varepsilon}_{t-i} \boldsymbol{\varepsilon}_{t-i}^{\prime}\right)+\sum_{j=1}^{s} \mathbf{B}_{i} \otimes \mathbf{H}_{t-j}
$$

where $I$ and $s$ are non-negative integers, $\mathbf{A}_{i}$ and $\mathbf{B}_{j}$ are symmetric matrices, and $\otimes$ denotes element-byelement multiplication. This method decreases the dimensions of the unknown parameters, but does not necessarily provide a positive-definite covariance matrix.

To guarantee the positive-definite requirement, Engle and Kroner (1995) have developed the BEKK model,

$$
\mathbf{H}_{t}=\mathbf{A A}^{\prime}+\sum_{i=1}^{l} \mathbf{A}_{i}\left(\boldsymbol{\varepsilon}_{t-i} \boldsymbol{\varepsilon}_{t-i}^{\prime}\right) \mathbf{A}_{i}^{\prime}+\sum_{j=1}^{s} \mathbf{B}_{i} \mathbf{H}_{t-j} \mathbf{B}_{j}^{\prime},
$$

where $\mathbf{A}$ is a lower triangular matrix and $\mathbf{A}_{i}$ and $\mathbf{B}_{j}$ are the $K \times K$ matrices of the parameters to be estimated. This model allows for dynamic dependence between volatility series, and also reveals how 
the conditional covariance matrix changes with new information (Engle, 2004). However, given the parameters in $\mathbf{A}_{i}$ and $\mathbf{B}_{j}$, we cannot make direct interpretations of the lagged values of volatilities (Tsay, 2005). The number of parameters also increases rapidly with I and $s$, which gives rise to the 'curse of dimensions' problem (Tsay, 2005). The full BEKK model is therefore primarily applied to cases with few dimensions.

To reduce the number of volatility equations, Bollerslev (1990) considers the case in which the correlation coefficient is time-invariant. Theoretically, $\mathbf{H}_{t}$ is decomposed as $\mathbf{D}_{t} \mathbf{R D}_{t}$, where $\mathbf{D}_{t}^{2}=\operatorname{diag}\left(\mathbf{H}_{t}\right)$ and $\mathbf{R}$ is the time-invariant correlation matrix. This model connects the conditional covariance and conditional variance through the conditional correlation matrix. However, it is often challenged, because in practice the correlation coefficient tends to change over time. Tse (2000), for instance, shows the correlations between national stock returns in Singapore, Japan, and Hong Kong to be time varying.

The DCC model has been developed by Engle (2002) with the following model specification.

$D_{i, t}^{2}=\left(1-\alpha_{i}-\beta_{i}\right) \bar{D}_{i}+\alpha_{i} \varepsilon_{i, t-1}^{2}+\beta_{i} D_{i, t-1}^{2}, \mathrm{i}=1, \ldots, K$,

$\mathbf{D}_{t}=\operatorname{diag}\left(d_{1, t, \ldots,} d_{K, t}\right)$,

$\mathbf{z}_{t}=\mathbf{D}_{t}^{-1} \boldsymbol{\varepsilon}_{t}$

$\mathbf{Q}_{t}=(1-a-b) \overline{\mathbf{Q}}+a\left(\mathbf{z}_{t-1} \mathbf{z}_{t-1}^{\prime}\right)+b \mathbf{Q}_{t-1}$,

$\mathbf{R}_{t}=\operatorname{diag}\left(\mathbf{Q}_{t}\right)^{-1 / 2} \mathbf{Q}_{t} \operatorname{diag}\left(\mathbf{Q}_{t}\right)^{-1 / 2}$, and

$\mathbf{H}_{t}=\mathbf{D}_{t} \mathbf{R}_{t} \mathbf{D}_{t}$

where $\bar{D}_{i}$ is the unconditional variance of residual series $\varepsilon_{i}, \mathbf{Q}_{t}$ is a positive-definite matrix, $\overline{\mathbf{Q}}$ is the unconditional covariance matrix of $\mathbf{z}_{t}$, and $\alpha_{i}, \beta_{i}, a$, and $b$ are non-negative scalar parameters that satisfy $a_{i}+\beta_{i} \in(0,1)$ and $a+b \in(0,1) .{ }^{1}$ When $a$ or $b$ is not zero, the time varying nature of the conditional correlations can be revealed by the $\mathbf{Q}_{t}$ matrix.

For this model, it is often argued that the main drawback is that the parameters $a$ and $b$ are scalar, so that all the conditional correlations have the same dynamics (Tsay, 2005). However, our research target is the inter-relationship between the different real estate sectors in Hong Kong. It is expected that their price movement follows each other closely. Hence, despite this drawback, the application of the DCC model to our study is reasonable.

\footnotetext{
1 These constraints are imposed to ensure that $D_{i, t}{ }^{2}>0, \forall i$, $t$ and $Q_{t}$ is positive-definite $\forall t$.
} 
The DCC model can be estimated in two steps. In the first step, univariate GARCH models are fitted for each residual series, and in the second step the standardized residuals from the first step are used to estimate the correlation parameters. More formally, the log-likelihood function of the entire model can be expressed as the sum of a volatility part and a correlation part, as follows.

$$
L(\theta, \phi)=L_{V}(\theta)+L_{C}(\theta, \phi),
$$

where the volatility component, $L_{V}(\theta)$, is the sum of the individual GARCH likelihoods, i.e.,

$$
L_{V}(\theta)=-\frac{1}{2} \sum_{t}\left(n \log (2 \pi)+\left.\log \mathbf{D}_{t}\right|^{2}+\boldsymbol{\varepsilon}_{t}^{\prime} \mathbf{D}_{t}^{-2} \boldsymbol{\varepsilon}_{t}\right),
$$

and the correlation part is

$$
L_{C}(\theta, \phi)=-\frac{1}{2} \sum_{t}\left(\log \left|\mathbf{R}_{t}\right|+\mathbf{z}_{t}^{\prime} \mathbf{R}_{t}^{-1} \mathbf{z}_{t}-\mathbf{z}_{t}^{\prime} \mathbf{z}_{t}\right) .
$$

The estimation procedure involves finding

$\hat{\theta}=\arg \max \left\{L_{V}(\theta)\right\}$

in the first step and then solving the maximum likelihood $\max _{\phi}\left\{L_{C}(\hat{\theta}, \phi)\right\}$ in the second stage by taking $\hat{\theta}$ as given (Engle, 2002). Thanks to this estimation approach, the DCC model overcomes the dimension problem which is usually faced by the full BEKK model, and can be applied to handle highdimension cases. In addition, it captures the time-varying nature of the correlation coefficients between time series, which is usually seen in real applications. Therefore, we adopt the DCC model specification in this study. ${ }^{2}$

\section{Data and the Hong Kong Property Market}

The data are obtained from the Rating and Valuation Department (RVD) of the government of the Hong Kong Special Administrative Region (HKSAR).3 We consider residential, office, and retail property in our analysis, using the monthly price indices ${ }^{4}$ of the three sectors. ${ }^{5}$ The sampling period is from 1993 to

\footnotetext{
2 Our study deals with a high-dimensional case, six series involved, which justifies the adoption of DCC approach rather than BEKK model.

3 The RVD is primarily responsible for the assessment of property prices and rents in Hong Kong, It provides property valuation advice to the government and compiles property market statistics. Its official website is http://www.rvd.gov.hk/en/home/index.htm and the data are collected from http://www.rvd.gov.hk/en/publications/pro-review.htm.

4 Monthly data are used for our study because as for real estate prices, the changes are not big between weeks. Therefore, instead of weekly data, monthly data are already sufficient to capture the volatility and correlation patterns.

5 The indices measure value changes by reference to the factor of price divided by rateable value of the properties rather than by reference to the price per square meter of floor area. By utilizing rateable value, both floor area and other qualitative differences between properties are considered. For more details of the index construction, please refer to the technical notes on the official website http://www.rvd.gov.hk/en/doc/statistics/15_technotes.pdf.
} 
2006, with the base period being January 1999. The characteristics and price index series used for each sector are discussed in the following sections.

\subsection{Residential property market}

The residential property market in Hong Kong consists primarily of high-rise condominiums. Due to the high population density and limited land supply in the region, residential housing units are typically smaller than 100 square meters. Less than $5 \%$ of residential properties have more than 100 square meters of saleable size, and these are generally considered to be luxury properties. ${ }^{6}$

The RVD publishes eight price indices for residential properties based on the saleable area. ${ }^{7}$ We use two of these indices in our analysis: the index for class A, B, and C units (apartments with a saleable area of less than 100 square meters), and the index for class $D$ and $E$ units (apartments with a saleable area of greater than or equal to 100 square meters). We denote the two series as Residential $A B C$, which represents the price movement for regular apartments, and Residential DE, which represents luxury apartments.

The monthly log returns of the two series are presented in Figure 1(A). In general, the two series followed each other closely in our sampling period, only that the Residential DE sector provides a bit higher returns.

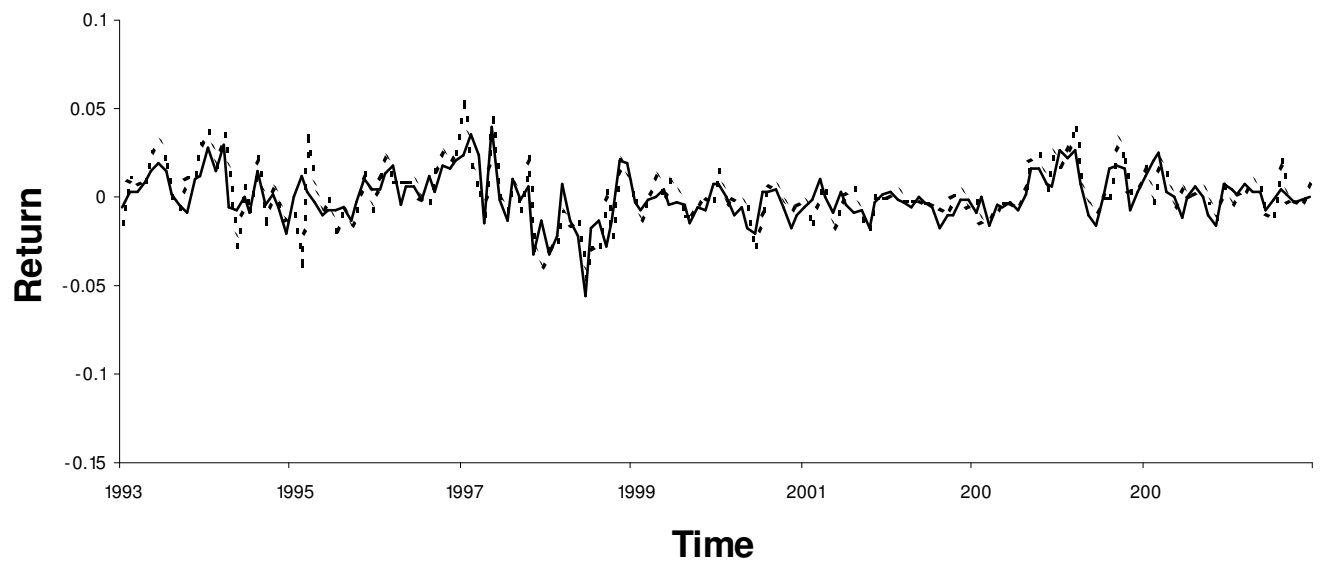

(A) MONTHLY LOG RETURNS FOR THE RESIDENTIAL ABC AND DE PROPERTY PRICE INDICES

6 For detailed statistics on the Hong Kong residential property market, see the Hong Kong Property Review published by the Rating and Valuation Department (www.rvd.gov.hk).

${ }^{7}$ The indices can be found at http://www.rvd.gov.hk/en/publications/pro-review.htm. 


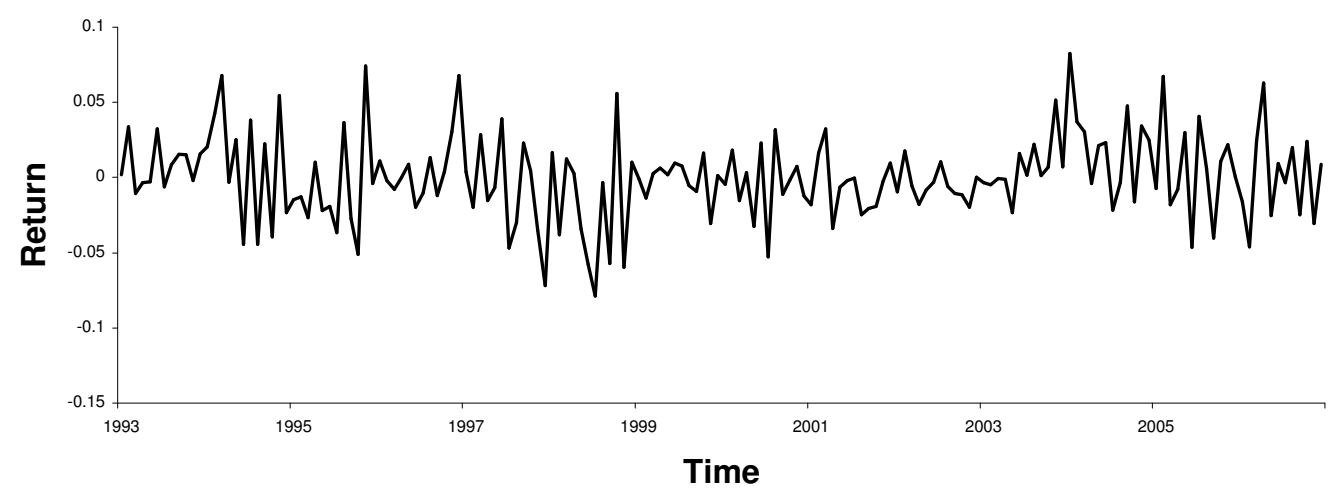

(B) MONTHLY LOG RETURNS FOR THE OFFICE A PROPERTY PRICE INDEX

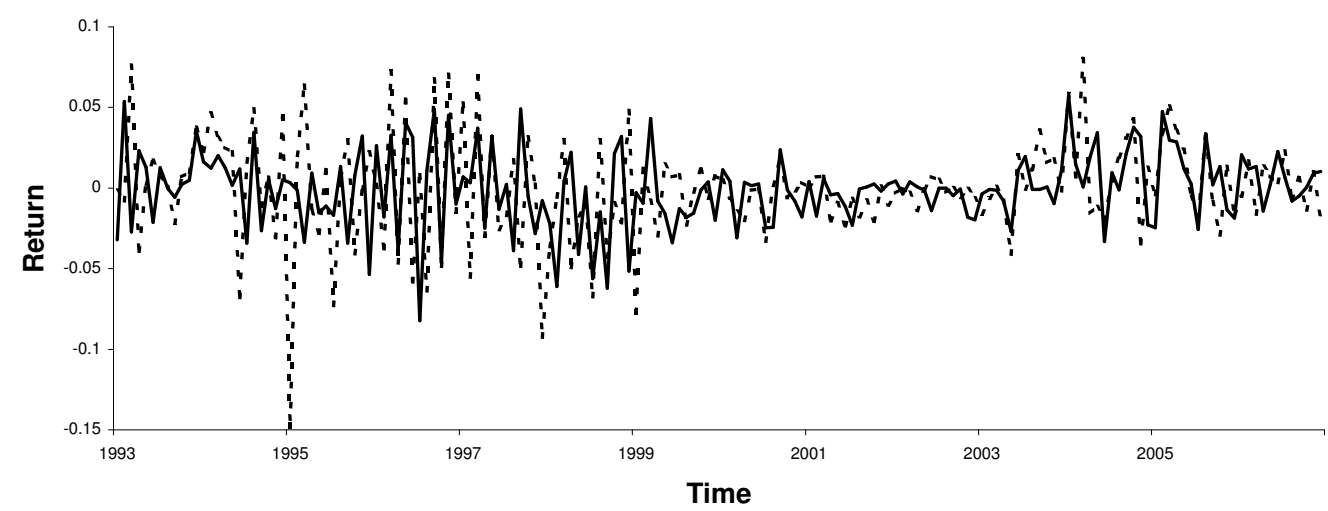

(C) MONTHLY LOG RETURNS FOR THE OFFICE B AND C PROPERTY PRICE INDICES

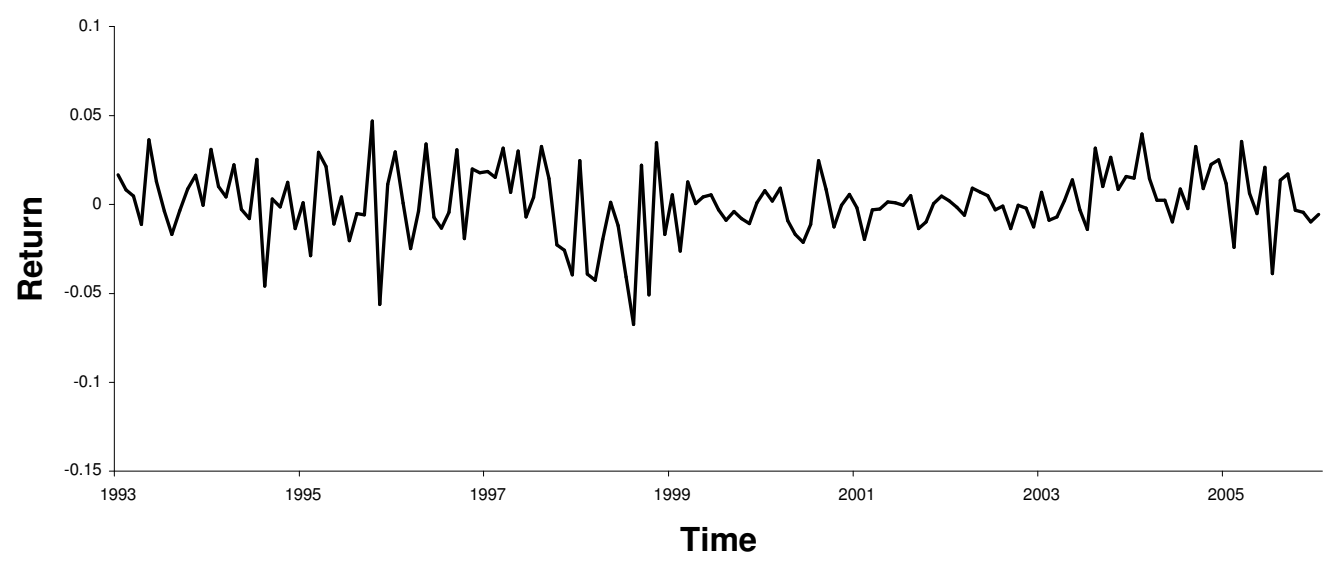

(D) MONTHLY LOG RETURNS FOR THE RETAIL PROPERTY PRICE INDEX

FIGURE 1. TIME PLOTS OF THE MONTHLY RETURNS FOR THE SIX TYPES OF PROPERTY FROM 1993 TO 2006 


\subsection{Office property market}

Offices in Hong Kong are classified by the RVD into three categories. Grade A offices are modern offices with high-quality finishes, Grade B offices have ordinary designs and good quality finishes, and Grade $\mathrm{C}$ offices are plain with basic finishes. The monthly log return series of the three grades are shown in Figures $1(B)$ and $1(C)$ (two plots are drawn, instead of one graph showing all three series, for clear presentation).

It can be seen in Figure 1(B) that the office price level in Hong Kong is generally influenced by regional economic development, with the impact of the 1997 Asian Financial Crisis and the 2003 SARS outbreak being quite obvious. Moreover, office returns have a more volatile pattern than the returns of residential sector. Among the three office series, Grade A exhibits the highest volatility, followed by Grades B and $\mathrm{C}$ office property. High quality is obviously the determining factor in office pricing, and it also brings higher risk to the investment in this sector.

\subsection{Retail property market}

According to the definition provided by the RVD, the retail property price index covers retail and other premises 'designed or adapted for commercial use, with the exception of purpose-built offices'. The monthly log return series for retail property is given in Figure 1(D). It is observed that the returns of retail property are more volatile than that of the residential sector, but relatively stable compared with the returns of the office property.

\subsection{Preliminary statistics}

Table 2 lists the descriptive statistics for the monthly returns. Luxury residential property (Class $D$ and Class $\mathrm{E}$ units) has the highest average monthly return, with only a small standard deviation, during the sampling period. In contrast, the returns for office property are negative for Grades $B$ and $C$, and the standard deviation of monthly returns for offices is generally very high. These results indicate that luxury residential property is the safest and most profitable property sector in which to invest in Hong Kong, whereas office property is the most risky, consistent with what is shown in Figure 1.

TABLE 2: DESCRIPTIVE STATISTICS OF THE SIX MONTHLY RETURN SERIES

\begin{tabular}{|l|c|c|c|c|}
\hline & Mean & Standard Deviation & Minimum & Maximum \\
\hline Retail & 0.0010 & 0.0190 & -0.0675 & 0.0469 \\
\hline Residential ABC & 0.0001 & 0.0132 & -0.0554 & 0.0402 \\
\hline Residential DE & 0.0015 & 0.0157 & -0.0463 & 0.0524 \\
\hline Office A & 0.0002 & 0.0282 & -0.0787 & 0.0826 \\
\hline Office B & -0.0003 & 0.0325 & -0.1482 & 0.0804 \\
\hline Office C & -0.0006 & 0.0238 & -0.0823 & 0.0572 \\
\hline
\end{tabular}


Table 3 provides the cross-correlation matrices of the six return series. To make explanation easier, we use the simplified notation proposed by Tiao and Box (1981). A cross-correlation matrix consists of three symbols, 't', '-', and '.', which indicate that the corresponding correlation coefficient is significantly positive, negative, and non-significant at the $5 \%$ level, respectively. Table 3 shows the significant crosscorrelations for all of the return series. We use the multivariate portmanteau test to further check the auto- and cross-correlations in the vector series $\mathbf{r}_{t}=\left\{r_{k\}}\right\}, k=1, \ldots, 6$, which represents retail, residential $A B C$, residential $D E$, office $A$, office $B$, and office $C$ property, respectively. The test statistic is denoted by $Q(m)$, where $m$ is the lag order. This test is a multivariate extension of the univariate Ljung-Box statistic, and was originally proposed by Hosking $(1980,1981)$ and Li and McLeod $(1981) .{ }^{8}$ For the six return series, we test that $Q(6)=565.55$ with a $p$-value which is close to zero. ${ }^{9}$ Significant auto- and cross-correlations occur in the return series, and thus the use of the vector autoregressive model $\operatorname{VAR}(p)$ for the mean is justified and the VAR-DCC model helps to reveal the inter-relationship amongst the returns in the residential, office, and retail property markets in Hong Kong.

TABLE 3 CROSS-CORRELATION MATRICES OF THE SIX MONTHLY RETURN SERIES (A) CROSS-CORRELATION MATRICES

\begin{tabular}{|c|c|c|c|c|c|c|c|c|c|c|c|c|c|c|c|c|c|c|}
\hline \multirow[b]{2}{*}{$k$} & \multicolumn{6}{|c|}{$\operatorname{Lag} 1$} & \multicolumn{6}{|c|}{$\operatorname{Lag} 2$} & \multicolumn{6}{|c|}{$\operatorname{Lag} 3$} \\
\hline & 1 & 2 & 3 & 4 & 5 & 6 & 1 & 2 & 3 & 4 & 5 & 6 & 1 & 2 & 3 & 4 & 5 & 6 \\
\hline 1 & -0.049 & 0.395 & 0.224 & 0.309 & 0.179 & 0.195 & 0.122 & 0.308 & 0.249 & 0.164 & 0.121 & 0.130 & 0.060 & 0.219 & 0.271 & 0.093 & 0.108 & 0.149 \\
\hline 2 & 0.331 & 0.484 & 0.461 & 0.270 & 0.183 & 0.155 & 0.264 & 0.282 & 0.312 & 0.254 & 0.181 & 0.132 & 0.132 & 0.171 & 0.189 & 0.167 & 0.016 & 0.155 \\
\hline 3 & 0.324 & 0.517 & 0.403 & 0.408 & 0.292 & 0.228 & 0.235 & 0.349 & 0.301 & 0.194 & 0.111 & 0.169 & 0.077 & 0.182 & 0.218 & 0.053 & 0.095 & 0.113 \\
\hline 4 & 0.289 & 0.378 & 0.400 & -0.139 & 0.016 & 0.102 & 0.153 & 0.175 & 0.126 & 0.193 & 0.242 & 0.101 & 0.127 & 0.171 & 0.243 & 0.082 & 0.071 & 0.083 \\
\hline 5 & 0.145 & 0.314 & 0.258 & 0.241 & -0.305 & 0.067 & 0.118 & 0.144 & 0.080 & 0.076 & 0.217 & 0.190 & 0.143 & 0.026 & 0.091 & 0.001 & -0.075 & -0.145 \\
\hline 6 & 0.181 & 0.252 & 0.222 & 0.135 & 0.077 & -0.204 & 0.140 & 0.194 & 0.295 & 0.129 & 0.277 & 0.036 & 0.038 & 0.237 & 0.050 & 0.275 & -0.097 & 0.086 \\
\hline
\end{tabular}

B) SIMPLIFIED NOTATION

\begin{tabular}{|c|c|c|c|c|c|c|c|c|c|c|c|c|c|c|c|c|c|c|}
\hline \multirow[b]{2}{*}{$k$} & \multicolumn{6}{|c|}{ Lag 1} & \multicolumn{6}{|c|}{$\operatorname{Lag} 2$} & \multicolumn{6}{|c|}{ Lag 3} \\
\hline & 1 & 2 & 3 & 4 & 5 & 6 & 1 & 2 & 3 & 4 & 5 & 6 & 1 & 2 & 3 & 4 & 5 & 6 \\
\hline 1 & . & + & + & + & + & + & . & + & + & + & . & . & . & + & + & . & . & . \\
\hline 2 & + & + & + & + & + & + & + & + & + & + & + & . & . & + & + & + & . & + \\
\hline 3 & + & + & + & + & + & + & + & + & + & + & . & + & . & + & + & . & . & . \\
\hline 4 & + & + & + & . & . & . & . & + & . & + & + & . & . & + & + & . & . & . \\
\hline 5 & . & + & + & + & - & . & . & . & . & . & + & + & . & . & . & . & . & . \\
\hline 6 & + & + & + & . & . & - & . & + & + & . & + & . & . & + & . & + & . & . \\
\hline
\end{tabular}

Note: $k=1, \ldots, 6$ represents retail, residential $A B C$, residential $D E$, office $A$, office $B$, and office $C$ property, respectively.

8 For details of the test, please refer to Hosking $(1980,1981)$ and Li and McLeod (1981).

9 We use the $Q(6)$ test to determine whether auto- and cross-correlations exist in the time series up to the sixth lag, where the rejection of the null hypothesis indicates the presence of auto- and cross-correlations. 


\section{Empirical analysis and discussion}

The measurements AIC and BIC are used to determine order $p$ of the vector autoregressive model. Table 4 shows the results of these two statistics for various orders. AIC suggests a VAR(3) model, whereas BIC supports a VAR(1) model. Applying the multivariate portmanteau test to the two models gives us $Q(6)=301.26(<0.01)$ for $\operatorname{VAR}(1)$ and $Q(6)=153.25(\approx 1.00)$ for $\operatorname{VAR}(3)$, where the numbers in parentheses denote the corresponding $p$-values. In other words, no auto- or cross-correlations are detected for the $\operatorname{VAR}(3)$ model up to the sixth lag, and therefore the $\operatorname{VAR}(3)$ model is selected for the mean. In exploring the residuals of the $\operatorname{VAR}(3)$ model, we find that GARCH effects are statistically significant in all of the series except for the office A property price index. ${ }^{10}$ We therefore construct a VAR(3) model using all six return series, but exclude office A property from the MGARCH model.

TABLE 4 ORDER SELECTION CRITERIA FOR THE VAR (P) MODEL

\begin{tabular}{|c|c|c|c|c|c|c|}
\hline $\boldsymbol{p}$ & $\mathbf{1}$ & $\mathbf{2}$ & $\mathbf{3}$ & $\mathbf{4}$ & $\mathbf{5}$ & $\mathbf{6}$ \\
\hline AIC & -5185.821 & -5183.263 & -5185.823 & -5132.832 & -5107.112 & -5050.337 \\
\hline BIC & -5060.030 & -4956.231 & -4864.432 & -4724.869 & -4621.436 & -4497.083 \\
\hline
\end{tabular}

TABLE 5 PARAMETER ESTIMATION FOR THE DCC $(1,1)$ MODEL

\begin{tabular}{|c|c|c|c|c|c|}
\hline$\alpha_{01}$ & $\begin{array}{l}6.9820 \mathrm{e}-05^{*} \\
(4.1016 \mathrm{e}-05)\end{array}$ & $a_{11}$ & $\begin{array}{l}0.7996 * * \\
(0.3384)\end{array}$ & $\beta_{11}$ & $\begin{array}{l}0.1367 \\
(0.1199)\end{array}$ \\
\hline$\alpha_{02}$ & $\begin{array}{l}4.3702 \mathrm{e}-06 \\
(3.5445 \mathrm{e}-06)\end{array}$ & $a_{12}$ & $\begin{array}{l}0.1057^{\star *} \\
(0.0376)\end{array}$ & $\beta_{12}$ & $\begin{array}{l}0.8575^{\star *} \\
(0.0536)\end{array}$ \\
\hline$\alpha_{03}$ & $\begin{array}{l}1.7313 \mathrm{e}-06 \\
(1.5499 \mathrm{e}-06)\end{array}$ & $a_{13}$ & $\begin{array}{l}0.0567^{* *} \\
(0.0210)\end{array}$ & $\beta_{13}$ & $\begin{array}{l}0.9223^{* *} \\
(0.0280)\end{array}$ \\
\hline$\alpha_{04}$ & $\begin{array}{l}4.5240 \mathrm{e}-04^{* *} \\
(1.8618 \mathrm{e}-04)\end{array}$ & $a_{14}$ & $\begin{array}{l}0.2148^{*} \\
(0.1105)\end{array}$ & $\beta_{14}$ & $\begin{array}{l}0.0212 \\
(0.3401)\end{array}$ \\
\hline$\alpha_{05}$ & $\begin{array}{l}2.7136 e-05^{*} \\
(1.4717 e-05)\end{array}$ & $\alpha_{15}$ & $\begin{array}{l}0.2115^{\star \star} \\
(0.0715)\end{array}$ & $\beta_{15}$ & $\begin{array}{l}0.7111^{\text {** }} \\
(0.0843)\end{array}$ \\
\hline a & & \multicolumn{4}{|l|}{$\begin{array}{l}0.0519^{* *} \\
(0.0254)\end{array}$} \\
\hline$b$ & & $\begin{array}{l}0.4604^{*} \\
(0.2546)\end{array}$ & & & \\
\hline
\end{tabular}

The numbers in parentheses are the standard errors.

${ }^{* *}$ Significant at the $5 \%$ level.

${ }^{*}$ Significant at the $10 \%$ level.

Note: $\alpha_{1 i}$ and $\beta_{1 i}$ are parameter estimates of each individual $\operatorname{GARCH}(1,1)$ model for series $i$, where $i=$ $1, \ldots, 5$ represents retail property, residential $A B C$ property, residential $D E$ property, office $B$ property, and office $C$ property, respectively. $a$ and $b$ are parameter estimates for equation $\mathbf{Q}_{t}=(1-a-b) \overline{\mathbf{Q}}+a\left(\mathbf{z}_{t-1} \mathbf{z}_{t-1}^{\prime}\right)+b \mathbf{Q}_{t-1}$ in model (1).

\footnotetext{
${ }^{10}$ We use both the Lagrange multiplier test and the Ljung-Box statistics $Q(m)$ test in this analysis (Tsay 2005, p. 101).
} 
Due to the small sample size and high-dimension characteristic of the problem, we choose the DCC technique to undertake the volatility analysis. $\operatorname{VAR}(3)-\operatorname{DCC}(1,1)$ model is adopted ${ }^{11}$. Applying the multivariate portmanteau test to the standardized residuals gives $Q(6)=112.83(0.98)$, and for the squared standardized residuals we find that $Q^{2}(6)=163.06(0.17) .{ }^{12}$ Therefore, no serial correlations or conditional heteroscedasticities remain in the residuals of the fitted model, which indicates that the model is adequate. Since our research target is the volatility analysis of Hong Kong property market, only estimation results of the DCC model are presented in Table 5 and those of the VAR model for conditional means can be obtained upon request from the authors.

\subsection{Conditional volatilities of the property price indices}

Table 5 summarizes the parameter estimates $\alpha_{1 i}$ and $\beta_{1 i}$ of each individual $\operatorname{GARCH}(1,1)$ model for series $i$, where $i=1, \ldots, 5$ represents retail property, residential $A B C$ property, residential DE property, office $B$ property, and office $\mathrm{C}$ property, respectively.

The constant term in each equation is close to zero, which indicates that, in the long run, the expected variance of all property returns is small. However, the conditional volatility is time varying. From Table 5 , we observe that the estimated parameters for the conditional variance equations are all positive and statistically significant at the $10 \%$ level, except for $\beta_{11}$ and $\beta_{14}$. This result confirms the presence of heteroscedasticities in all of the return series, although retail and office $B$ returns show a shorter persistence in shocks to volatility than the other property types. The sum of $\alpha_{1 i}+\beta_{1 i}$ is close to one in most cases, which is evidence of volatility clustering, as shown in Figure 2.

In the time plots of conditional volatility (Figure 2), we can see two periods of high volatility around 1997 and 2004. In the first period, the Hong Kong property market underwent a market boom and suffered the effects of the 1997 Asian Financial Crisis, whereas the second period saw the 2003 SARS outbreak and a market recovery in 2004 as a result of favourable government policies..$^{13}$ The first wave of high volatility (from 1996 to 1999) is larger than the second (from 2003 to 2004), possibly because the impact of the 1996/1997 market boom and the 1997 Asian Financial Crisis was greater than that of the 2003 SARS outbreak and the 2004 market recovery. ${ }^{14}$ This result implies that the level of conditional volatility

$11 \mathrm{DCC}(1,1)$ is selected because the model is both adequate (the residuals of both the mean and the variance are white noise) and parsimonious.

${ }_{12} Q^{2}(m)$ is used to test for the presence of auto- and cross-correlations in the squared standardized residual series.

13 The Hong Kong property market reached its lowest point in 2003 during our sample period. In the second half of 2003, several favorable policies were issued by the Chinese government to stimulate the Hong Kong economy, the most successful of which were the Individual Visit Scheme (http://www.tourism.gov.hk/ english/visitors/visitors_ind.html) and the Closer Economic Partnership Agreement (http://cepa.tdctrade.com/).

14 Take the residential property market as an example: the prices increased by 42.42\% from August 1996 to July 1997, and then dropped by 36.88\% between August 1997 and July 1998; between July 2002 and June 2003, when SARS hit Hong Kong, the property prices dropped by only $16.36 \%$, and during the following year improved in value by $27.91 \%$. 
is related to the magnitude of the impact of events. The high turbulence during these periods indicates that the market is sensitive to external shocks, and thus real estate investment is more risky during major political and economic events in Hong Kong.

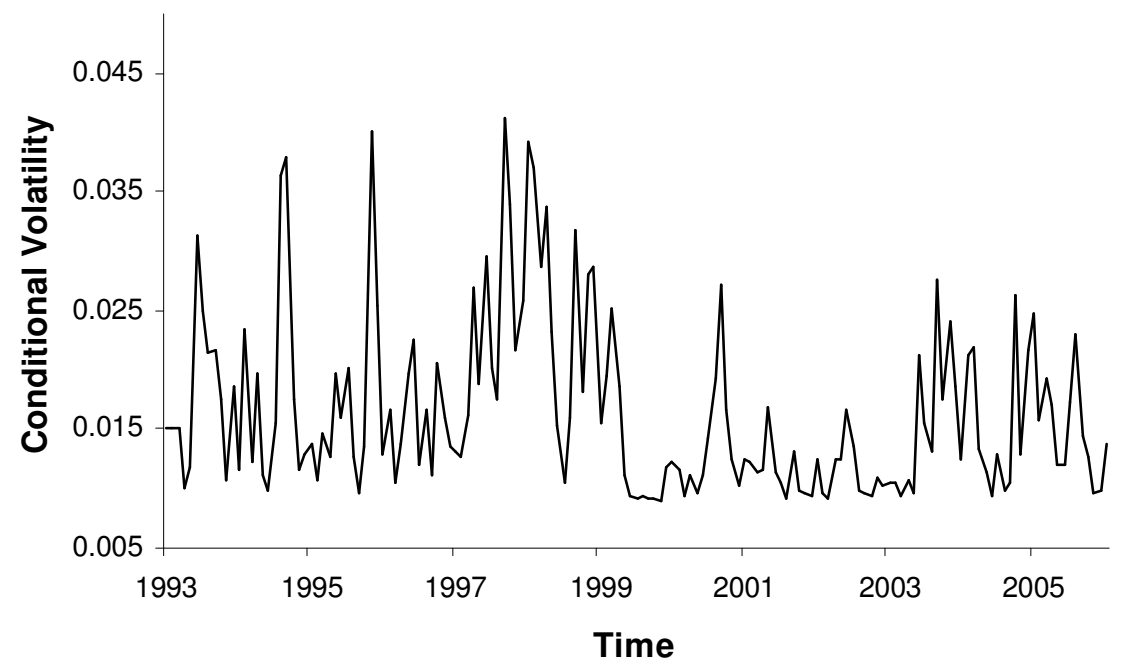

(A) RETAIL PROPERTY

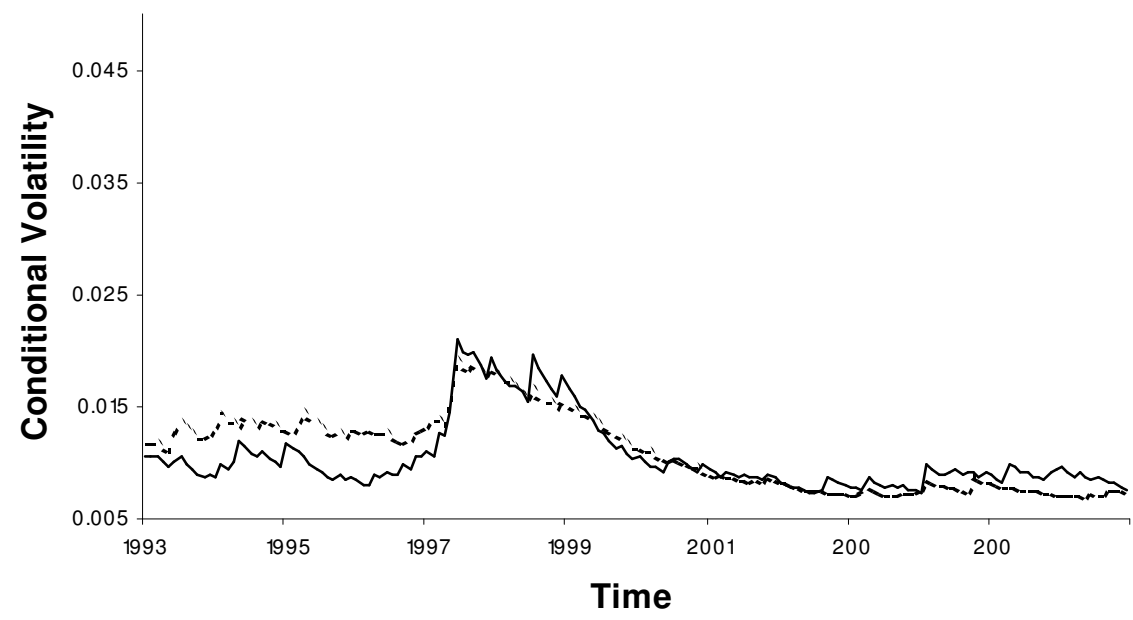

(B) RESIDENTIAL ABC PROPERTY AND RESIDENTIAL DE PROPERTY 


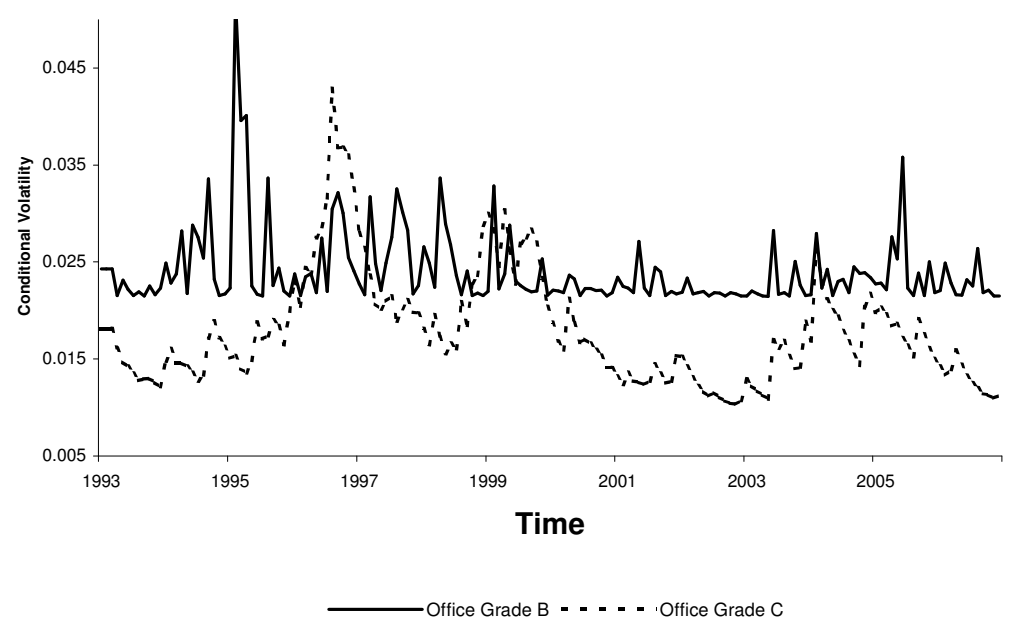

(C) OFFICE B AND OFFICE C PROPERTY

FigURE 2 (A, B, C) TIME PLOTS OF THE VOLATILITIES FROM THE FITTED DCC $(1,1)$ MODEL

Figure 2 shows that, on average, the residential sector experienced the smallest level of volatility during the sampling period. Although there is speculation in the residential property market, the fundamental driving force of this sector is housing demand, which is not likely to change significantly over a short period. It is therefore not a surprise to observe a lower level of fluctuations in this market.

For office property, the volatility pattern becomes simpler the higher the quality. Office A property demonstrates no GARCH effects, office $B$ units show ARCH effects only, and grade $C$ offices reveal significant GARCH effects. Volatility clustering is evident for office $C$ property in Figure $2(\mathrm{C})$, with the conditional volatility of the return series closely following the economic cycle (for example, the volatility increases during market booms and decreases during the period of market recession between 1999 and 2003). For grade B offices, the conditional volatility responds to shocks (for example, the spikes around year 1997 and 2003), but returns to a given level (approximately 0.024) quickly. The conditional volatility of grade A offices is not estimated in our $\mathrm{DCC}(1,1)$ model, as no GARCH effect is detected in the return series. This indicates that the returns for higher quality office property in Hong Kong are relatively stable.

In conclusion, the conditional volatilities of both residential and office $\mathrm{C}$ property change over time, with the turbulence in returns tending to be higher during major events. A similar time-varying pattern is also observed in the conditional volatility plots for retail and office B property, except that the response to shocks (for example, market booms) lasts for a shorter period before the volatility returns to a given level. 


\subsection{Conditional correlations of the property price indices}

To explore the correlations between the property return series, we focus on the parameters $a$ and $b$ in model (1). Table 5 shows both parameters to be statistically significant at the $10 \%$ level, and thus the adoption of the DCC model is justified. Figure 3 presents the time-varying correlation coefficients of the pairwise property return series.

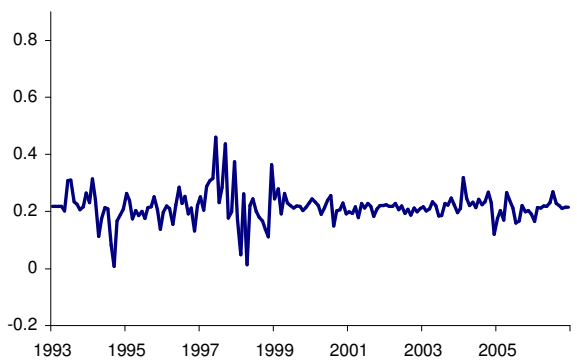

(A) RETAIL AND RESIDENTIAL ABC PROPERTY

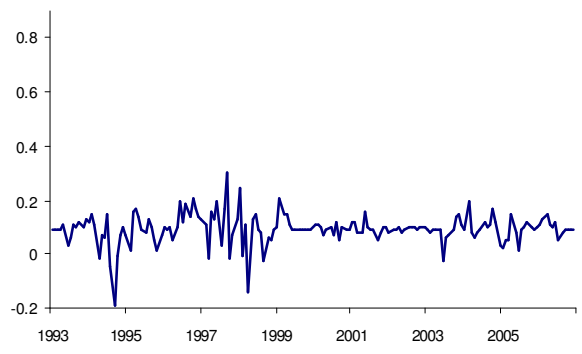

(C) RETAIL AND OFFICE B PROPERTY

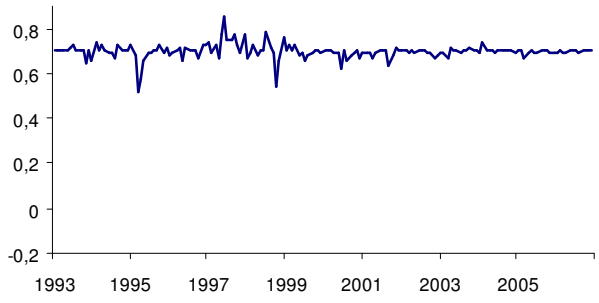

(E) RESIDENTIAL ABC AND RESIDENTIAL DE PROPERTY

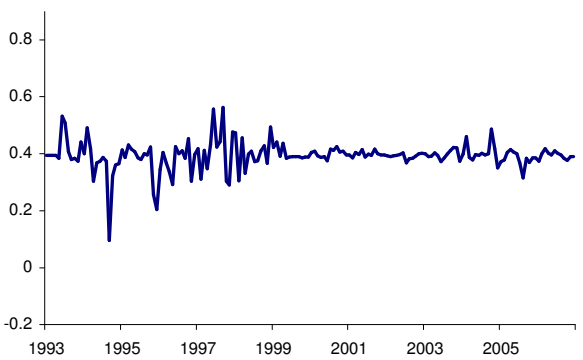

(B) RETAIL AND RESIDENTIAL DE PROPERTY

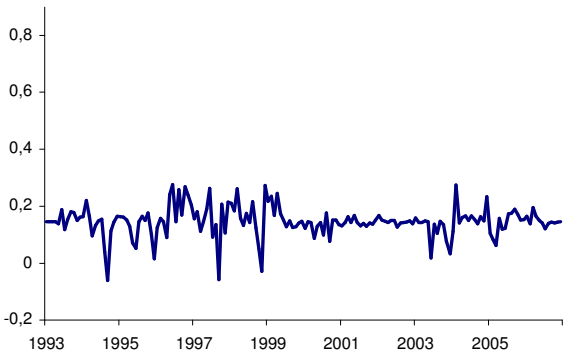

(D) RETAIL PROPERTY AND OFFICE C PROPERTY

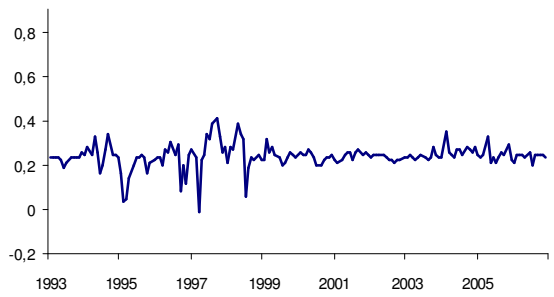

(F) RESIDENTIAL ABC AND OFFICE B PROPERTY 


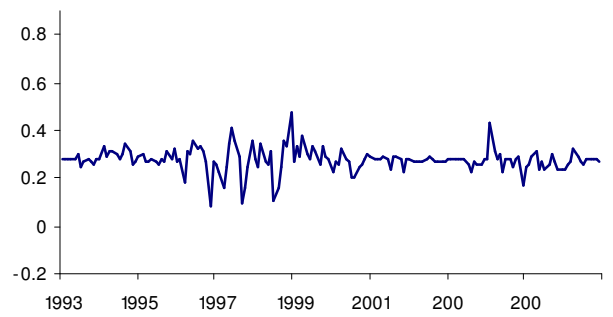

(G) RESIDENTIAL ABC AND OFFICE C PROPERTY

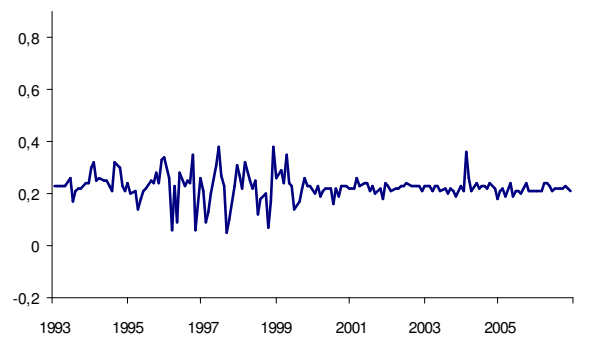

(i) Residential DE and office C property

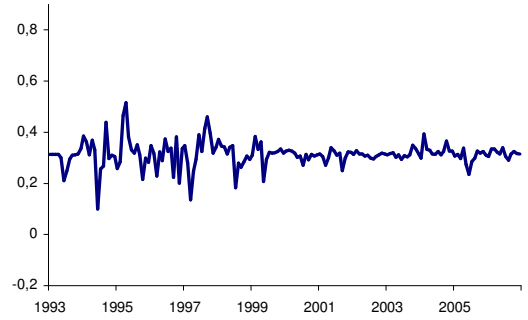

(H) RESIDENTIAL DE AND OFFICE B PROPERTY

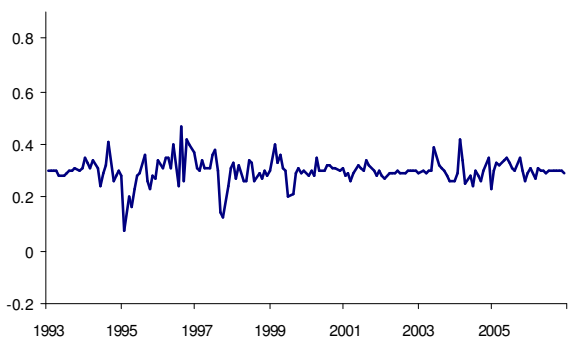

(J) OFFICE B AND OFFICE C PROPERTY

FIGURE 3 TIME-VARYING CORRELATION COEFFICIENTS FROM THE FITTED DCC $(1,1)$ MODEL

The general pattern is that the correlation coefficients show large fluctuations during the 1997 Asian Financial Crisis. After the crisis, the market entered its recession phase, during which the pairwise correlations remain fairly stable. After 2004, the Hong Kong real estate market started to recover, and the correlations of the return series remain relatively stable but with greater fluctuations than during the recession period. Between 1997 and 1998, the Asian Financial Crisis caused several destructive shocks to the property market, and the high fluctuations reflect the turbulent and panicked state of the market at this time. During the recession, transactions were inactive and the market almost went into hibernation, and as the market was in a stagnant but stable stage, the conditional correlations between the property sectors show steady patterns. The current property market is in a transition phase between recession and healthy growth, which started to occur in 2004. The associations between the various property types exhibit correspondingly greater fluctuations than for the period 1999-2003, although the average value of the pairwise correlation coefficients is stable between 0.2 and 0.3 for most cases.

Analysis of Figure 3 shows the average correlation between residential $A B C$ and $D E$ property to be the highest, at about 0.7 . The correlation between office $B$ and $C$ property returns is 0.3 on average, which is higher than most of the other correlations. Overall, the within-sector correlations are higher than the cross-sector correlations. As investment products with similar natures, the within-sector property returns are more closely associated. 
From Figure 3, we observe the average values of pairwise cross-sector associations (see Table 6). Both retail and office property have greater correlations with residential property, which indicates a smaller chance of diversification between residential property (especially residential DE property) and other property in the Hong Kong real estate market. For example, if an investment portfolio includes retail property, then adding office property to the portfolio would be a better choice than exposure to the residential sector.

TABLE 6 AVERAGE CROSS-SECTOR CORRELATION COEFFICIENTS OBTAINED FROM FIGURE 4

\begin{tabular}{|l|c|c|c|c|c|}
\hline & Retail & Residential ABC & Residential DE & Office B & Office C \\
\hline Retail & -- & 0.2 & 0.4 & 0.1 & 0.15 \\
\hline Residential ABC & -- & -- & 0.7 & 0.23 & 0.28 \\
\hline Residential DE & -- & -- & -- & 0.31 & 0.22 \\
\hline Office B & -- & -- & -- & -- & 0.3 \\
\hline Office C & -- & -- & -- & -- & -- \\
\hline
\end{tabular}

\section{Conclusions}

This study conducts an empirical analysis of the time-varying volatility and correlations of the residential, retail, and office property sectors in Hong Kong using the DCC approach. The flexible model specification enables us to reveal the characteristics of and the inter-relationships between the three property sectors, which should provide useful guidance for real estate investment and the future development of REITs in Hong Kong.

We find that all of the property types show strong auto- and cross-correlations, which indicates that the sectors are closely related to each other. In all three sectors, the levels of conditional volatility are higher when major political and economic events occur. We also observe that the conditional correlation coefficients fluctuated greatly between 1993 and 1998, and then remain relatively stable at a low level (around 0.2 in many cases) after 1999. In addition, the real estate investment returns within each sector follow each other closely, whereas the correlations across sectors are smaller. These findings indicate the possibility of balancing investment portfolios amongst the three sectors in the Hong Kong property market. However, exposure to the residential sector may reduce the chance of investment diversification because of the higher correlation of this sector with other property sectors.

\section{REFERENCES}

Bollerslev, T. (1990). Modeling the coherence in short-term nominal exchange rates: A multivariate generalized ARCH approach. Review of Economics and Statistics 72: 498-505. 
Bollerslev, T., Engle, R.F. and Wooldridge, J.M. (1988). A capital-asset pricing model with time-varying covariances. Journal of Political Economy 96: 116-131.

Chau, K.W., Wong, S.K. and Yiu, C.Y. (2007). Housing quality in the forward contracts market. Journal of Real Estate Finance and Economics 34(3): 313-325.

Cotter, J. and Stevenson, S. (2006). Multivariate modeling of daily REIT volatility. Journal of Real Estate Finance and Economics 32(3): 305-325.

Engle, R.F. (2002). Dynamic conditional correlation: A simple class of multivariate GARCH models. Journal of Business and Economic Statistics 20: 339-350.

Engle, R.F. (2004). Risk and volatility: Econometric models and financial practice. The American Economic Review 94(4): 405-420.

Engle, R.F. and Kroner, K.F. (1995). Multivariate simultaneous generalized ARCH. Econometric Theory 11: $122-150$

$\mathrm{Fu}, \mathrm{Y}$. M. and Ng, L. K. (2001). Market efficiency and return statistics: Evidence from real estate and stock markets using a present-value approach. Real Estate Economics 29(2): 227-250.

Glascock, J.L., Lu, C.L. and So, R.W. (2000). Further evidence on the integration of REIT, bond, and stock returns. Journal of Real Estate Finance and Economics 20(2): 177-194.

Hosking, J.R.M. (1980). The multivariate portmanteau statistic. Journal of the American Statistical Association 75: 602-608.

Hosking, J.R.M. (1981). Lagrange-multiplier tests of multivariate time series models. Journal of the Royal Statistical Society Series B 43: 219-230.

Hui, E.C.M. and Yue, S. (2006). Housing price bubbles in Hong Kong, Beijing and Shanghai: A comparative study. Journal of Real Estate Finance and Economics 33(4): 299-327.

Hudson-Wilson, S., Gordon, J.S., Fabozzi, F.J., Anson, M.J.P. and Giliberto, S.M. (2005). Why real estate? and how? where? and when? Journal of Portfolio Management, Real Estate Special Issue $12-22$.

La Grange, A. (2001). Housing, home ownership and social change in Hong Kong. Urban Studies 38(1): 219-220.

La Grange, A. and Pretorius, F. (2000). Ontology, policy and the market: Trends to home-ownership in Hong Kong. Urban Studies 37(9): 1561-1582.

La Grange, A. and Pretorius, F. (2005). Shifts along the decommodification-commodification continuum: Housing delivery and state accumulation in Hong Kong. Urban Studies 42(13): 2471-2488.

Leung, C. K. and Feng, D.D. (2005). What drives the property price-trading volume correlation? Evidence from a commercial real estate market. Journal of Real Estate Finance and Economics 31(2): 241-255.

Li, W.K. and McLeod, A.I. (1981). Distribution of the residual autocorrelations in multivariate ARMA time series models. Journal of the Royal Statistical Society Series B 43: 231-239.

Ling, D. and Naranjo, A. (2002). Commercial real estate performance: A cross country analysis. Journal of Real Estate Finance and Economic, 24: 119-142.

Lu, C.L. and So, R.W. (2005). Return relationships between listed banks and real estate firms: Evidence from seven Asian economies. Journal of Real Estate Finance and Economics 31(2): 189-206. 
Maroney, N. and Naka, A. (2006). Diversification benefits of Japanese real estate over the last four decades. Journal of Real Estate Finance and Economic, 33: 259-274.

Michayluk D., Wilson, P.J. and Zurbruegg, R. (2006). Asymmetric volatility, correlation and returns dynamics between the U.S. and U.K. securitized real estate markets. Real Estate Economics, 34(1): 109-131.

Stevenson, S. (2004). Testing the statistical significance of real estate in an international mixed asset portfolio. Journal of Property Investment and Finance, 22: 11-24.

Tiao, G.C. and Box, G.E.P. (1981). Modeling multiple time series with applications. Journal of the American Statistical Association 76: 802-816.

Tsay, R.S. (2005). Analysis of financial time series. New Jersey: John Wiley \& Sons, Inc.

Tse, R.Y.C. (2002). Estimating neighbourhood effects in house prices: Towards a new hedonic model approach. Urban Studies 39(7): 1165-1180.

Tse, Y.K. (2000). A test for constant correlations in a multivariate GARCH model. Journal of Econometrics 98: 107-127.

Wong, S.K., Yiu, C.Y., Tse, M.K.S. and Chau, K.W. (2006). Do the forward sales of real estate stabilize spot prices? Journal of Real Estate Finance and Economics 32(3): 289-304.

Xiao, Q. and Tan, G.K.R. (2007). Signal extraction with Kalman filter: A study of the Hong Kong property price bubbles. Urban Studies 44(4): 865-888.

Yiu, C.Y. and Wong, S.K. (2005). The effects of expected transport improvements on housing prices. Urban Studies 42(1): 113-125. 